\title{
Student Reflection on the Development of Intercultural Competence through the Education Abroad Experience
}

\author{
Michaela Lukešová ${ }^{1}$ \\ ${ }^{1}$ Tomas Bata University in Zlín, Faculty of Humanities, Czech Republic \\ Correspondence: Michaela Lukešová, Tomas Bata University in Zlín, Faculty of humanities, Mostní 5139,76001 \\ Zlín, Czech Republic. Tel: 42-057-603-7418. E-mail: lukesova@fhs.utb.cz
}

Received: November 18, 2014 Accepted: April 7, 2015 Online Published: July 6, 2015

doi:10.5539/ass.v11n21p1 URL: http://dx.doi.org/10.5539/ass.v11n21p1

\begin{abstract}
This study is devoted to the topic of intercultural competence. It aims to determine what intercultural competence students acquire through education abroad experience. Based on the results of our research we will introduce synthesized and identified fundamental structures and on their basis we will present research questions/hypotheses. We are not neglecting the recommendation for practice. We present recommendations for the development of these key competences through ideas such as "pre-departure intercultural training", which would help students to find their way around their new environment and gain a deeper understanding of the cultural context.
\end{abstract}

Keywords: intercultural competence, intercultural communication, internationalization, education abroad experience

\section{Introduction}

The rise of globalisation has led to an increase in constant interaction between people, cultures and civilisations, and mobility and migration have resulted in the creation of a multicultural society. Scientists, teachers and students alike all agree that the world around them has changed both politically and economically, as well as in cultural, social and technological terms (Janebová, 2009). Universities are a part of the broader society - the contemporary globalisation process, as well as of society itself. Universities are becoming a microcosm of society, a "melting pot", a place where individuals gather not only in the general sense of the word, but men and women with their own histories. And therefore these educational institutions should strive to develop key skills that will help students to succeed in our rapidly changing society. As they develop these key skills, students become "global-ready graduates" or "global citizens" (Hunter, White, \& Godbey, 2006), who have mastered key intercultural competences.

One possible means of developing intercultural competence in university students is internationalisation, which becomes a natural part of universities. From the viewpoint of internationalisation, universities are places which provide their students and employees with an internationalised environment to enable them to develop the intercultural competences they need in today's global society, and they aim to assure that international experience becomes a natural part of their studies for all students. To what extent do experience abroad and the internationalised environment of universities develop the aforementioned intercultural competences, or what are the key competences developed by students who have participated in a study visit abroad? This is the main question we attempt to answer through this study, which analyses the reflections of students who have returned from spending several months on a study visit abroad. This study aims to determine what key abilities and skills students acquire during a study visit abroad; however, we also attempt to find the most effective way of implementing cultural aspects into the educational curriculum in order to develop key abilities and skills and also ways of supporting students to go on study visits abroad.

\section{The Theoretical Background of Intercultural Competence from the Point of View of Intercultural Communication}

Experts specialising in intercultural communication and the development of intercultural competence in various different contexts have started to explore the question of what it means to be an effective communicator and how it is possible to develop the communication skills of people in an intercultural environment. This has gradually 
led to the need to identify the different aspects of effective communication, with the aim of developing knowledge and improving the standard of research surveys.

Based on their research studies, Ruben (1977 see also Ruben \& Kealey, 1979) recognised that the observable behaviour of the individual rather than knowledge of other cultures is a more suitable variable for analysing effective communication and identified seven behavioural evaluation components of communication competence (communicative competence): a) display of respect, b) interaction posture, c) orientation to knowledge, e) empathy, f) self-oriented role behavior, g) interaction management a h) tolerance for ambiguity.

Another research approach came from Hammer, Gudykunst, and Wiseman (1978) in which 24 abilities were identified based on a review of literature concerning intercultural effectiveness. Three dimensions were specified: a) the ability to deal with psychological stress, b) the ability to effectively communicate, and c) the ability to establish interpersonal relationships.

However, Spitzberg (1989) argued that competence is not only effectiveness. It also involves Appropriateness. Appropriateness refers to "avoiding the violation of valued rules or expectancies" whereas effectiveness is "the achievement of valued objectives or rewards" (Spitzberg, 1989, p. 250). Based on these key components of intercultural communication competence we may therefore define it as "the ability to effectively and appropriately execute communication behaviors to elicit a desired response in a specific environment" (Wiemann, 1977 In Chen 1990, p. 247).

If we focus on the concept of intercultural competence, we must say that we come across a number of different theoretical approaches. We present the outcome of our research, which identifies and assesses the intercultural competence of students who have experience of a study visit abroad (education abroad experience). One author who explores the topic of intercultural competence in relation to internationalisation is Deardorff (2006), who identified and evaluated students' intercultural competence as the result of internationalisation (Identification and Assessment of Intercultural Competence as a Student Outcome of Internationalization). This study seeks to determine a definition and appropriate assessment methods of inter-cultural competence as agreed on by a panel of internationally known intercultural scholars. The result of the research was a consensual definition in which multicultural competences are seen as "the ability to communicate effectively and appropriately in intercultural situations, which is based on intercultural awareness, skills and attitudes". This research led to the creation of two models of intercultural competence - pyramid and procedural. In the pyramid model, the lower levels (based on requisite attitudes, knowledge and skills) support and enhance the higher levels (those of desired internal and external outcomes). At the top, some of the desired external outcomes are the ability to both behave and communicate effectively to achieve goals. The desired internal outcomes include aspects of an individual's frame of reference, including aspects of adaptability, flexibility, and empathy. These are supported by both knowledge and skills. Finally, the base of the pyramid rests on requisite attitudes, including those of respect, openness, and curiosity.

Intercultural competence therefore means the optimal integration of knowledge, mindfulness and communication skills when interacting in problematic situations in an appropriate, effective and adaptive manner. The criteria of communication appropriateness, effectiveness and adaptability may serve as evaluation criteria to determine whether intercultural conflict communication is perceived as competent or incompetent (Ting-Toomey, 2009).

Appropriateness means the extent to which a certain type of behaviour is seen as correct and in line with the expectations of others. In order to be able to act "correctly" in a cultural situation, not only do we need the relevant awareness of the broader context which could affect interaction, but we also require specific knowledge of the conflict, i.e. what constitutes appropriate or inappropriate behaviour and how such behaviour may influence the constructive or destructive outcome of the conflict. According to Ting-Toomey (2009), appropriateness in communication is a process of culturally-sensitive attunement, in which individuals not only acquire knowledge of values and norms in a conflict situation, but are also able to skilfully apply that knowledge in practice.

Effectiveness corresponds to communication skills, which encompass verbal and non-verbal behavioural manifestations that enable individuals to attain their communication goals in intercultural interaction through appropriate and effective action. In order to achieve an effective communication strategy in conflict situations, both parties must be capable of employing a wide range of verbal and non-verbal forms of behaviour, and must also be mentally and behaviourally flexible and adaptable.

Adaptability refers to our ability to adapt to different styles of communication and behaviour and to adapt to a new cultural environment. It implies our mental, affective and behavioural flexibility when dealing with an intercultural conflict. Adaptability signalises our attunement to the perspectives, interests, goals and approaches 
of others, as well as our willingness to modify our own behaviour and aims to best suit the conflict situation in question (Ting-Toomey, 2009).

No matter how intercultural competence is theorized within intercultural communication. Scholars seem to agree on at least free core assumptions. First, most intercultural communication scholars agree that intercultural competence should be conceptualized based on cognitive, affective and behavioral approaches (Bennett, 2009). Second, the end reset should be communication that is considered both effective and appropriate. Third, intercultural competence is culture-general. According to Bennett is intercultural competence a set of cognitive, affective and behavioural skills and characteristics that support effective and appropriate interaction in a variety of cultural contexts.

Table 1. Intercultural competence as a set of cognitive, affective and behavioral skills

\begin{tabular}{ccc}
\hline Cognitive dimension & Affective dimension & Behavioral dimension \\
\hline Cultural self- awareness & Curiosity & Relationship building skills \\
Culture-general knowledge & Cognitive flexibility & Behavioural skills: listening, problem solving \\
Culture-specific knowledge & Motivation & Empathy \\
Interaction analysis & Openmindedness & Information gathering skills \\
\hline
\end{tabular}

According to Morgensternová, Šulová (2009) cognitive competence consists of the ability to have a realistic view of myself ("inner self") and the ability to realize our "cultural self". It represents our cultural heritage which is characterized by the values, traditions and norms of our culture. Inner self and cultural self is forming our socio-cultural identity. There can also include the ability to realize our prejudices, stereotypes and think tolerantly. This category includes our ability to acquire and process knowledge about foreign culture, ability to properly analyze the behavior of individuals from different cultures, understand the differences between domestic and foreign culture and to be aware of them.

Affective competencies are related to our experience of the situation. Among very important attributes of affective competencies belong cultural sensitivity and empathy. Adaptability is key in the processing and the adoption of new cultural patterns of behavior. Adaptability is understood in a broad sense as the ability to adapt to new conditions. We understand it as art to maintain peace of mind, a feeling of safety and health at significant change in living conditions.

Behavioral competencies are the best seen externally, and can be the best influenced. They include the full range of complex skills, for example: the art of communication, conflict resolution, team work and problem-solving skills in intercultural situations. During communication is especially authenticity, listening skills, realize and respect the formal rules in a foreign culture and others.

Kim (1991) seems to summarize all of these findings with the hypothesis that intercultural communication competency results from adaptability, or the individual's capacity to suspend or modify some of the old cultural ways, to learn and accommodate some of the new cultural ways, and to creatively find ways to manage the dynamics of cultural difference/unfamiliarity, intergroup posture, and the accompanying stress (p. 268). More precisely, Kim suggested that there are three dimensions that relate to this concept of cross-cultural adaptability or intercultural communication competence: the cognitive dimension (an individual's interpretive mechanism or structures that assign meaning to messages), the affective dimension (an individual's motivation or willingness to accommodate intercultural encounters), and the behavioural dimension (an individual's abilities to be flexible and resourceful in using his or her cognitive and affective skills). Essentially, effective intercultural communicators must have an understanding of cultural communication differences, an ability to overcome those barriers, and a desire to use those skills.

This study explores the thoughts of students who have been on a study visit abroad, with the aim of identifying key components of intercultural competence. Therefore, the primary question is as follows: To what extent do experience abroad and the internationalised environment of universities develop the aforementioned intercultural competences, or what are the key competences developed by students who have participated in a study visit abroad?

\section{Method}

This study is based on phenomenological investigation, i.e. the description and analysis of the experiences of students of Tomas Bata University in Zlín, which participated in a European Union certified educational 
programme aimed at supporting cooperation and mobility in all spheres of education, and one of the requirements of this programme is that the student must have studied abroad (education abroad experience). The aim of the certified programme is to prepare students for constantly changing society and to develop their intercultural competences, as well as to support students in their efforts to master skills that will help them in their own personal development and will increase their employability.

The aim of the study is to obtain feedback from students involved in the programme, i.e. to acquire a self-assessment report on the following: What experience students acquired through international experience and what specific abilities and skills they mastered?

\subsection{Collection of Data}

All the students who participated in the survey were contacted by the researchers by email. We acquired the contact details of all the students through faculty coordinators, who keep records of student mobility abroad. The first email sent to the students contained a request asking them to take part in the survey, with further details of the research - the aims of the research and a brief justification of the research problem.

A total of 33 students were contacted, i.e. all those involved in student mobility from 2011/2012 to 2013/2014. As this is a relatively broad time frame, we had to assume that some students had already graduated and their contact details had changed, and also had to count on the fact that some students would not be interested in participating in the research. In the end, a total of 10 students agreed to take part in the survey. This research sample we consider sufficient as well as Creswell (1998) recommends, in the framework of the phenomenological study, to realize interviews with 10 to 15 individuals.

All the students who participated in the survey have experience of a study visit in a country in Europe (Slovakia, Denmark, Finland, Germany, Austria and Estonia).

As research tools analysing intercultural competence through quantitative strategy continue to be unsystematic and inconsistent, with many experts focusing on the theoretical aspects of intercultural competence and debates over the components of competence and attempts to validate those components with the aim of subsequently gauging the effectiveness of intercultural communication, we opted for a qualitative strategy.

We collected the data through a qualitative phenomenological interview, in which participants were asked to reflect on their experience with mobility and describe how it was important to them. The respondents were asked to construe and explain the meaning of their conduct in specific social situations (Hendl, 2008).

In the first interview the participants were asked to give their thoughts on their general experience with cultural differences. The aim of this question was to place the individuals' experience into context by obtaining as much information as possible from them in relation to the topic.

The question was: What is your personal experience with cultural differences?

The second interview focused on the details of that experience. The interview revealed specific details of the participants' experience in relation to the topic. The questions were as follows:

Describe how you adapted during your international experience?

How was it to work (deal) with people from different cultures?

Describe your own experience using the local (official) language (communicating or speaking the local language).

During the third interview the participants were asked to give their thoughts on their experience, i.e. to identify the specific abilities and skills they acquired during their time spent abroad. The question was as follows:

Please describe your specific abilities and skills, the knowledge and attitudes you used or acquired during your international experience.

\subsection{Data Analysis}

In order to assure a descriptive phenomenological analysis we use bracketing, intuition, analysis and description. When using bracketing we realise our preconceived concepts and ideas about the phenomenon and when collecting the data we strive to understand the importance the participants ascribed to the given experience.

In the intuitive phase the aim is to gain a precise understanding of the importance of the students' experience with the phenomenon we are studying. We compare the various different data segments and the categories and topics that result, while using a content analysis (coding, categorisation and definition of themes). The intuitive phase will be followed by an in-depth description of the importance of those experiences (Hendl, 2008). 
From the narratives of the participants we will try to detect and isolate thematic content of experiences of participants by using the method of selective approach according to Van Maanen (1988). In the frame of this approach, the researcher analyzes each sentence in the text. Once researcher identifies themes, he/she approaches to reflection and interpretation. This phase will be followed by in-depth description of meaning (Hendl, 2008) and we will introduce synthesized and identified fundamental structures and on their basis we will formulate research questions/hypotheses.

\subsection{Results of the Research}

On the basis of students' thoughts about their experiences abroad, we can say that the development of abilities and skills can be monitored in terms of the cognitive, behavioural and affective aspects. This part of the work is devoted to the results of our research survey.

\subsubsection{Description of Acquired Cognitive Competencies}

Cognitive competences in the broader sense of the word mean the field of knowledge, skills and abilities that goes to form our thought software. This software or equipment contains the whole range of our findings, experience and information not only about foreign culture, but also about the person himself or herself. Which of these were identified by the survey participants?

Students focused particularly on the findings they acquired about foreign cultures, how they adapted to the way people thought in the foreign culture and to the process of understanding the differences between their own culture and the foreign one.

Many of the students' comments were about specific aspects of the new culture, such as religion, as one student stated: "I wasn't well prepared for it, especially not as a non-religious person. It's not that they tried to force their faith on us (my other classmate from the Czech Republic), but their certainly argued its case." (H, Slovakia).

Other comments concerned information the students had acquired relating to the economic, political or historical aspects of the environment in question, or focused on comparing that culture with their own. One respondent's answer reflects all the others:

"As regards money, Finns are better paid than Czechs. This is mostly down to the fact that for some time now Finland has used the euro, but even so, in comparison with the Czech Republic, the standard of living and housing are better. The Finns love to have a good time, so there are some social events and concerts going on in town every day." ( $P$, Finland).

A major role in developing knowledge of the local community was played by guides (the Buddy system), who were there for the students all the time they were abroad. "We all went on various trips, to festivals and cultural events, which helped us to gain a better understanding of the country." (K, Finland).

There are also courses taught as part of lessons which influence the development of these key skills. "I attended a course: Identity in Motion, which was aptly named. We were a group of 17 students, everyone from a different part of the world. Our task was to create scenes depicting our culture and compare that culture with Austria. It was extremely interesting and informative. Over time, we realised that at the beginning we'd had a fairly different opinion of other cultures." $K$, Finland).

Last but not least there are also the "host mother/father", who can have a very positive influence on students. "My landlord was very pleasant, ...he was interested in my culture, so we used to get together and inspire one another." (S, Austria).

Students devoted a great deal of attention to making detailed comparisons of the situation in the Czech Republic and in the country they stayed in. The first topic was comparing the teaching styles used.

"At the school we had several joint projects we had to work on with people from various different countries. It was a great experience." (B, Denmark).

"We had to adapt to a completely different style of teaching. Everything was based on group work, so it was very important to get on with the people in the group and be able to discuss things with them. (S, Denmark).

"The greatest difference was probably in the style of teaching, practice and certain opinions, which were enormously influenced by the local faith." (H, Slovakia).

Another very common topic mentioned when comparing the two cultures was the behaviour of people in the Czech Republic as compared with the behaviour of the local people (e.g. local ethnic and national minorities). Comparisons were particularly along the lines of: People in the Czech Republic behave in this way, and people 
in that country behave like that, either in a positive or negative manner. If a person is able to acquire and process findings about a new culture and analyse the behaviour of individuals from different cultures, understand the differences between their home culture and foreign culture, this means they have mastered a very important part of cognitive competence.

As part of cognitive competences students also developed their ability to take a realistic look at themselves and become aware of their "cultural me" (cultural identity). "Cultural me" means the cultural heritage we carry with us and which encompasses the values, traditions and norms of our national culture.

"I got to know new cultures, and realised how happy I am that I live in the Czech Republic." (J, Denmark).

"Everything is new for you. I realised many things there and a lot of people inspired me to do things which had never occurred to me in the Czech Republic." (S, Austria).

Another important aspect of cognitive competence is awareness of our prejudices and stereotypes and the ability to think "tolerantly". The expression "awareness" is important, as it cannot be completely separated from stereotypes or prejudices, as they simplify the world as we perceive it and make it easier to read. In this case we particularly mean enhancing positive attitudes towards foreign cultures and being "culturally" open and tolerant.

"Of course I got to know lots of new people, characters and opinions. Those people and experiences taught me to be more tolerant, adaptable and creative." (P, Finland).

"Not focusing on the differences between people based on their country of origin, skill colour or faith was something I thought I wouldn't have a problem with. However, at the beginning I noticed in myself that a person (who is not used to multicultural environments) constantly compartmentalises others based on these very attributes." (B, Denmark).

"Thanks to my flatmates I learned to be more tolerant." ( $V$, Austria).

\subsubsection{Description of Acquired Affective Competencies}

Affective competences relate to how we experience a particular situation. Key concepts here are therefore intercultural sensitivity and adaptability. This particularly concerns our sensitivity to a foreign culture and our ability to adapt. It also involves empathy, i.e. the ability to empathise with foreign mentalities and their specifics and to better interpret foreign behavioural models and correctly interpret emotions in the culture in question, in relation to the knowledge we possess about that culture (the cognitive component of multicultural competence). Here we clearly see the interconnectedness and the correlation between the individual components of intercultural competence - cognitive, affective and behavioural.

A major role in the development of key abilities and skills was played by students' previous multicultural experience. If students had already participated in a similar programme or work placement or have the chance to travel during their leisure time, this also reduces problems with adapting to a new environment and students learn to cope with cultural differences very quickly.

"Before my study visit I had spent two and a half months during the holidays in Austria (holiday job), which was a great advantage for me." (V, Austria).

"As it wasn't the first time I had been abroad for some time alone, I adapted to the cultural differences very quickly." (S, Austria).

"Although it was the first time I had been away from home for a long time, I had already travelled all over Europe and through part of Asia and Africa, so I was generally used to seeing people of other nationalities with other customs and other languages." (Z, Austria).

Adaptability means the ability to maintain one's mental well-being and a feeling of being healthy and safe, even when one's living conditions have changed dramatically.

"Mobility allows you to adapt not only to the cultural differences of the country you have chosen to visit, but also the cultural differences of different people from all over the world." (S, Denmark).

"Most of all you probably acquire and enhance your own qualities and eventually you'll see if those are enough or not, and you have to learn to adapt. That's most likely what it's all about adapting. (H, Slovakia).

Intercultural courses were offered to enable students to adapt to the conditions of their chosen country as quickly as possible and to enable them to communicate effectively and appropriately in a variety of intercultural situations, i.e. courses which helped the students to broaden their understanding of the local community. 
"For two hours a week we had a course in Estonian culture, where they taught us cultural customs and national dishes and drinks; we also went to various museums, where we learned more about their culture. However, ESN also prepared plenty of interesting trips and events for us with local and other students. The international dinner, for example, was a great event, at which teams from the various different countries cooked their national dishes and have a presentation about their country." (S, Estonia).

According to the students, dealing with cultural differences is not just about understanding the environment in which we are to live, but also greatly depends on mastering a foreign language. When asked about how they adapted during their international experience, the students also referred to how long it took them to develop their language skills, which is a competence component discussed further below (behavioural competence).

Most of the students described not only the specifics of the culture in question, comparing aspects such as traditions, customs and the value system, but also the importance of empathising with foreign mentalities and their specifics and appropriately interpreting foreign behavioural models.

"First of all I had to recognise and understand how people behaved and why. I would never have believed what a long process that could be." (S, Denmark).

“... I also had to adapt to various different forms of behaviour where I lived, which was very multicultural." (B, Denmark).

Another of the main topics relating to the affective aspects of intercultural competence is the ability to deal with various different perspectives and be open-minded.

"As I came across a very diverse range of cultural differences, I had (if I really wanted to learn something) to really open up, to be "open-minded”. ( $B$, Denmark).

"I also learned how to be more open and communicative and to not be afraid of new things and experiences." (P, (Finland).

"My multicultural and pro-European sentiments were enhanced by new experiences. I am more open to the world than I was before I left, and have more of a desire to travel. (B, Denmark).

On a similar note, the participants also described how their time abroad had become an experience that had changed or at least affected their lives.

"I realised that I didn't want to be one of a thousand graduates, but that I wanted to be a confident student, one matured by experience, who would know what she wanted as soon as she finished her studies. I would be able to decide, as I would be aware of my options. And that's probably me all over." (S, Austria).

\subsubsection{Description of Acquired Behavioral Competence}

The third important category of acquired competence comprises behavioural competence. In this category particularly emphasis was placed on acquiring experience in relation to the development of language and communication skills, as well as on describing the development of a wide range of different life experiences.

Many times students commented on the problem of language abilities and skills. Many of the participants described how they had improved their language skills through their international experience and mentioned this development especially in relation to various aspects ranging from passive knowledge of the language, active use of the language, and the number of foreign languages they had learned.

One very interesting fact that all the students agreed on was that English is a universal language. English helped them a great deal in communicating during their international experience, even though that country used a different official language.

“It was a neutral language for us all.” (H, Slovakia).

"If there was a conflict, I was unable to speak a word of German. Only English. (Z, Germany).

"Most of all I used English ... the biggest problem could be when a person is unable to speak any language other than his native tongue, in which case it would be very difficult to integrate oneself into an international community. (Z, Germany).

The universality of English did not make it more effective to communicate with the local people and other students from other countries, but also meant it could be used when learning local languages.

"Every week I went to Finnish lessons, which were taught in English." (K, Finland).

Students also mentioned the approximate length of time needed to adapt to a foreign language, which in their view took around two weeks. 
"It took me around 2 weeks to adapt to the fact that English was used everywhere, and I used to have to go and rest for a while in the afternoons, as I felt my head bursting from the information overload. However, people are very adaptable and after two weeks I had pretty much effortlessly adapted to the conditions in Denmark." (B, Denmark).

One of the many reasons for using English as a universal language was the fact that the local language is too complicated, or is not spoken anywhere else in the world.

"My study visit wasn't really long enough for me to master the local language. And Danish isn't spoken anywhere else outside Denmark, so you could say I didn't really have the need or the time to learn that language." (B, Denmark)

However, there were some students who were interested in mastering at least the basics of the local language, and so they attended courses.

"First and foremost my friends and I saw our Danish language course as being a meaningful way of spending our leisure time, and secondly as something truly interesting. (S, Denmark).

"During my studies I had the chance to attend an option Danish language course, and as I was interested in learning something about the language, I set myself the task of learning to speak some Danish.” (J, Denmark).

"Before starting school I had attended a German language course and there we had a large ethnic mix. Classmates from France, Denmark, Brazil, Vietnam, the USA, Greece, Palestine, Iraq, Jordan, Slovenia, Holland, etc. The course lasted for two weeks and we were all "forced" to speak only German in class. We were only allowed to use English during break times and after school. (Z, Germany).

The students also tried to make meaningful use of what they had picked up of the local language when communicating with the local people, during their work experience, etc.

"I tried to use Finnish, or at least a few words or short sentences, when communicating with my friends from other countries or with our Finnish friends and also in the hospital in which I was doing my work experience. The patients were happy to engage in at least a short conversation. " (K, Finland).

"I spoke Estonian to the patients in the hospital, as well as in shops and wherever it was needed." (S, Estonia)

The students also commented on their experience with non-verbal communication and how valuable it is to develop those skills.

"Communication was obviously very difficult at the beginning, but I managed to get my meaning across using body language.” (S, Estonia).

"...it was sometimes harder with the dialect, which was very strong in the area I was staying in, so I had absolutely no chance of understanding some of the older people, but I got around everything using my hands and feet." (S, Austria).

The prevalence of comments about the importance of non-verbal communication is significant for two reasons. The first is that the students were immersed in an environment in which they had to use a foreign language that they still did not feel confident using and did not want to rely entirely on their ability to speak. Therefore, gestures and other non-verbal strategies became essential in order to maintain communication. The second reason is the relative isolation of the participant or time spent in an environment in which the local community does not use English as a universal language, meaning that students had to quickly learn the language that was officially used in that environment in order to be able to communicate with the people in the community.

Ability to cooperate, communicate and work in an intercultural team, as well as to respect others, understand one's role in the team, facilitate and contribute towards the development of the team are some of the main skills involved in the behavioural component of intercultural competence. And, from what the students said, it is obvious that the ability to cooperate in a team is a crucial skill if one wants to succeed in an intercultural situation.

"It was sometimes difficult to make one's voice heard in a larger group, but you could say that we all respected one another. Cooperation was always brisk and we were able to do a lot of work as a team in just a few days." (B, Denmark).

"Once we'd got past the language barrier, there was nothing to stop us from working together on our group projects." (S, Denmark).

Perceiving and correctly interpreting conflict situations and learning strategies for resolving intercultural conflicts/problems are important skills that are needed by anyone who enters an intercultural environment. From 
what the participants said, it is clear that that they do not have much experience with conflicts or how to resolve them. Most often they faced problems relating to teamwork, but managed to respond appropriately by drawing on their adaptability skills.

"Of course, when working together there were people who did not join in much and wanted to just be "carried by the group", and it was hard to work with those - luckily these were merely exceptions." (B, Denmark).

"Students from Romania have a completely different sort of day than we do. They really don't worry about being late for everything. They sit at the computer at night and are not bothered that their flatmates want to sleep and relax. I will always have fond memories of my classmates from Romania, although perhaps tinged with a touch of bitterness about their inconsiderate behaviour towards others." (S, Denmark), and an almost identical opinion is also given (J, Denmark).

Elsewhere, with a view to acquired behavioural skills, emphasis was placed on acquired basic life experience. Many of the participants described new experiences through which they acquired skills such as: independence, responsibility, using local public transport, abiding by unwritten local rules, exchanging money, etc. This is all reflected in the answer given by a student describing his experience from Denmark: "Once I had got hold of an old bike, which I used to ride in all weathers (just like everyone else), I felt like a Danish citizen. I also had to adapt to being away from home and to the responsibility of having money on my account which had to keep me going for the rest of my stay. I had to adapt to the local prices and the unwritten rules about being out alone in the big city. Also to various different types of behaviour in the place where I lived, which was very multicultural." (B, Denmark).

"I learned to be independent, responsible, active. I had to deal with everything myself; I had practically no help from anyone and the results were always my own accomplishments." (P, Finland).

\section{Discussion}

The partial results of the research enable us to interpret the in-depth description of the importance of such experiences for the entire group of participants. We therefore explore the findings and experience we have gained through our contact with the participants when collecting this data.

It is evident that experience abroad, or a study visit abroad, had a significant influence on the students. We can say that we have achieved our objectives and identified the components of intercultural competence students acquired during their stay abroad.

The participants learned something new about the culture in question, and learned to apply what they had learnt in the real life of the community. Most of the participants stated that it was their first experience living abroad (apart from holidays with parents, for example), where they were left to rely on their own resources, skills and experience, and had to take responsibility for their own behaviour. This fact also highlighted the importance of developing language skills (and knowledge of a foreign language) and non-verbal communication, which earlier they might have taken for granted. Even more important is the fact that many participants claimed that their experience had prompted them to be more open, patient and flexible.

One student stated: "I realised that I didn't want to be one of a thousand graduates, but that I wanted to be a confident student, one matured by experience, who would know what she wanted as soon as she finished her studies. I would be able to decide, as I would be aware of my options. And that's probably me all over."

We will not repeat the results that we have presented above, but we will introduce synthesized and identified fundamental structures of the realized research. Key acquired abilities and skills, we see at the level of cognitive, affective and behavioral. We also recognize identified specific skills and abilities that students acquired on the basis of the study abroad experience. The following model presents these fundamental structures.

We can discuss how the findings are consistent with previous knowledge on intercultural competence. Intercultural competencies can be categorized into three elementary areas: cognitive, affective and behavioral. One of the most critical components of cognitive intercultural competence is self-exploration or the development of our own cultural awareness and identity (Hofstede, 2004). Identity, as well as understanding the lens through we each view the world, becomes a foundational point for exploring intercultural competence. As Kim (2009) discusses, research has shown that an inclusive identity orientation and a strong identity security (the degree to which an individual feels secure in his or her identity) are both important in successful intercultural engagement, leading to greater degrees of adaptability, flexibility and cultural empathy, all elements of intercultural competence. Indeed, Kim sees this inclusive identity orientation and identity security as ,a necessity for anyone striving to develop meaningful and fruitful intercultural relationships" (p. 62). 
Table 2. Fundamental structure of intercultural competence

\begin{tabular}{|c|c|}
\hline \multicolumn{2}{|l|}{ Cognitive dimension } \\
\hline \multirow[t]{2}{*}{ Knowledge of cultures } & Approaching the way of thinking in a given culture. \\
\hline & Awareness of the differences between own and foreign cultures. \\
\hline Cultural identity & Awareness of my own "cultural background" - ie. cultural self. \\
\hline & $\begin{array}{l}\text { Knowledge of models of identity development and process of acculturation. } \\
\text { Self-awareness - be aware of my own values, attitudes, norms and their } \\
\text { significance for my personality. }\end{array}$ \\
\hline $\begin{array}{l}\text { Enhancing self-reflection, } \\
\text { self-conception }\end{array}$ & $\begin{array}{l}\begin{array}{l}\text { Willingness to self-development in my own values, worldview and } \\
\text { prejudices. }\end{array} \\
\end{array}$ \\
\hline $\begin{array}{l}\text { Preventing prejudice and } \\
\text { stereotypes, to be tolerant }\end{array}$ & $\begin{array}{l}\text { Becoming aware of our prejudices, stereotypes and to be open-minded and } \\
\text { tolerant. }\end{array}$ \\
\hline \multicolumn{2}{|l|}{ Affective dimension } \\
\hline $\begin{array}{l}\text { Intercultural adaptability and } \\
\text { sensitivity }\end{array}$ & $\begin{array}{l}\text { Sensitivity to foreign cultures and adaptability. } \\
\text { Ability to use own cultural knowledge and sensitivity to culturally sensitive } \\
\text { and better cooperation. }\end{array}$ \\
\hline Empathy & $\begin{array}{l}\text { Empathy with foreign mentalities, their specifics and better interpret } \\
\text { foreign behavior patterns. }\end{array}$ \\
\hline Open mind & The ability to deal with different perspectives. \\
\hline $\begin{array}{l}\text { Experiencing } \\
\text { relationships }\end{array}$ & $\begin{array}{l}\text { Awareness of interpersonal distance and closeness in a given culture and } \\
\text { other specifics. }\end{array}$ \\
\hline \multicolumn{2}{|l|}{ Behavioral dimension } \\
\hline Language skills & $\begin{array}{l}\text { Mastering the universal language to communicate effectively with people } \\
\text { from other cultures. } \\
\text { Mastering the official (local) language. }\end{array}$ \\
\hline Intercultural communication & $\begin{array}{l}\text { Communication without communication noise and confusion. } \\
\text { Ability to work with non-verbal communication. } \\
\text { Respect formal rules in foreign cultures. }\end{array}$ \\
\hline $\begin{array}{l}\text { Capacity to cooperate and work } \\
\text { in intercultural teams }\end{array}$ & $\begin{array}{l}\text { Respect of others. } \\
\text { Understanding own role in a team. } \\
\text { Contribute to effective team collaboration. }\end{array}$ \\
\hline $\begin{array}{l}\text { Interpretation of intercultural } \\
\text { conflict situations and } \\
\text { intercultural conflict resolution }\end{array}$ & $\begin{array}{l}\text { Ability to identify problems and intercultural conflicts. } \\
\text { Ability to learn different strategies to address and manage intercultural } \\
\text { conflicts. }\end{array}$ \\
\hline
\end{tabular}

Based on the research, we found out, that students see abilities and skills very important for adapting to a new culture during study abroad experience. It is adaptability and language skills. Adaptability is the ability to adapt and accommodate one's own behavior to people from other groups. One important aspect is to know more than one language, but language skills does not translate automatically into intercultural skill. One can be a fool in more than one language, and it is quite easy to behave foolishly in an unfamiliar culture. Language does not automatically endow one with cultural knowledge or the ability to adapt to different communicative styles or behaviors. This can be supported by the Deardorff (2004) study in which the experts did not reach consensus on the role of language in intercultural competence. Interestingly, one successful leader noted that „I used to think language skills were as important as cultural adaptability, but I now believe adaptability is far more important... It can be very dangerousto pick people because they have language skills and then to find out they have very little cultural adaptability and little interest in adapting" (Brake, 1997, p. 62). With or without language skill, the ability to encourage in chameleon-like behavior remains critical to functioning interculturally (Pusch, 1994).

Another of the main topics relating to the affective aspects of intercultural competence is the ability to deal with various different perspectives and be open minded. For example Hunter et al. (2006) define global competence: Having and open mind while actively seeking to understand cultural norms and expectations of others, leveraging this gained knowledge to interact, communicate and work effectively outside one's environment.

As we already said, perceiving and correctly interpreting conflict situation and learning strategies for resolving intercultural conflicts are important skills that are needed by anyone who enters an intercultural environment. According Ting-Toomey (2009) as the global economy becomes an everyday reality in most societies, 
individuals will inevitably encounter people who are culturally different in diverse workplaces and social environments. Developing intercultural conflict competence within larger intercultural competence setting is critical because conflict creates further perceptual distortions and emotional flooding in the cultural encountering process. Sharpening the knowledge, mindfulness, and skills of intercultural conflict competence can simultaneously enhance general intercultural competence tendencies and vice versa. Under emotional anxiety and stress, even if an individual is well honed in general intercultural competence, she or he might still be overwhelmed by her or his verbal and nonverbal inaptness and awkwardness. Thus, it is important to pay close attention to the topic of intercultural conflict competence within the broad umbrella of intercultural competence.

Ability to cooperate, communicate and work in an intercultural team are some of the main skills involved in the behavioral component of intercultural competence. According to Fantini (2000) is ability very important too because, intercultural competence consists of the following components: First, the attributes most commonly cited in the literature are flexibility, humor, patience, openess, interest, curiosity, empathy, tolerance for ambiguity, and suspending judgments. The three interrelated areas are the ability to establish and maintain relationships, the ability to communicate with minimal loss or distortion, and the ability to cooperate to accomplish tasks of mutual interest or need. The four dimesions are knowledge, (posotive) attitudes (or affect), skills, and awareness.

In research it is important to examine the validity. That is the validity of the obtained results due to the fact. Degree of validity is the answer to the question of whether we examine what we want to investigate, and it is one of the requirements of objectivity. Our phenomenological research can be validated by using ecological and construct validation.

Ecological validity determines the applicability of the results in practice. Ecological validity is a form of an external validity. External validity represent a problem for qualitative researchers because their tendency to employ case studies and small samples. Some test may very well measure a hypothetical construct, but in practice the results are unenforceable, or do not show in everyday life. This is particularly important to identify in a laboratory test. In our case, we can say that there was no laboratory research.

The ecological validity is very crucial for our research, because, as we have said, is oriented towards practice. The results of our research are objective and applicable in practice, because we realized the research that presents an experiential profile of respondents on their real life. We selected the students who participated in a long-term stay abroad. It means that they spend at least one semester (five months) abroad. Based on this long experience they were able to adequately answer our questions. The questions for an interview were formulated in such a way as to check whether individual students / respondents objectively describe their experiences.

Based on the results of the research we have created the fundamental structure of intercultural competence. After comparing this structure with theoretical studies, we can say that the result represents the theoretically determined construct, and we applied the construct validity.

Internal validity means whether there is a good match between researchers' observations and theoretical ideas they develop. Le Compte, Goetz (in Bryman, 2012) argue that internal validity tends to be a strength of qualitative research, because the prolonged participation in social life of a group over a long period of time allows the researcher to ensure high level of congruence between concepts and observations.

To summarize, we can determine the potential drawbacks together with a recommendation how they can be remedied. This study is based on only 10 students' description of their own education abroad experiences. Therefore, there is still space for the implementation of research and data are still asking for insight into the experience with intercultural competences. We are aware that the analysis is not intended to be representative of all education abroad experiences. Future studies could investigate more participants' experiences and more written accounts to obtain more comprehensive result.

Another limitation of this study may be the questions we asked students, which could be very specific and prompt. These prompt questions shaped how students reflected on their experiences and what stories were reported.

The limits of the research can also relate to the research sample of respondents. Data was collected from one university. The sample of the students is limited to the cultural background of the student population at that specific university. To address this, one possibility would be to compare similar type of data across institutions that have similar education abroad programs.

This research examined the experiences of respondents on the basis of one research method. Future studies may consider triangulation by investigating different types of data including, for example, observation of participants, 
or quantitative-based pretests and posttest of cultural sensitivity. The triangulation method may provide a more holistic understanding of students' intercultural behaviors (Deardorff, 2009). Longitudinal research will also need to assess apecific predeparture and postdeparture training programs to see what impact these programs have on the continuing development of intercultural competence in education abroad students.

In the field in which we carried out our research survey it was found that there is a lack of any form of education for students who are preparing for a study visit abroad. There is a lack of education at the level of "pre-departure intercultural training". The increasing importance of intercultural sensitivity in the global and multicultural society has led many scholars and experts to examine the concept from different perspectives. Practically, the concept has been integrated into intercultural training programs that are initiated to develop the ability of intercultural sensitivity. Those training programs include "T-groups," critical incidents, case studies, role playing, and cultural orientation programs (Seidel, 1981).

A common goal of intercultural training is to develop intercultural sensitivity by increasing awareness of cultural differences and attempts to develop one's communication potential while lessening the likelihood of intercultural misunderstandings (Cargile \& Giles, 1996). In other words, the intercultural training programs aim to "develop an appreciation and understanding of cross-cultural differences and to acquire some of the necessary abilities, such as an increased awareness and sensitivity to cultural stimuli and better human relations skills" (Seidel, 1981, p. 184). Morgan and Weigel (1988) pointed out that the major purpose of the above mentioned training programs is to develop intercultural sensitivity, and intercultural sensitivity is a prerequisite for intercultural effectiveness.

As an essential element to the positive outcome of intercultural encounter, the importance of intercultural sensitivity can also be examined from the six general categories of intercultural training programs: affective training, cognitive training, behavioral training, area simulation training, cultural awareness training, and self-awareness training (Gudykunst, Hammer, \& Wiseman, 1977; Seidel, 1981).

According to Gudykunst, Ting-Toomey, and Wiseman (1991), the affective training is designed to increase trainees' motivation and sensitivity to communication with people from other cultures and ethnic groups. The cognitive training is to promote understanding of cultural differences and similarities. The behavioral training provides skill training so that participants learn to communicate more effectively with people of other cultures.

The area simulation training requires that participants spend a period of time in a cultural or ethnic neighborhood and to interact fully with the residents in order to gain the real experience of intercultural encounters. The cultural awareness training requires participants to understand the aspects of culture that are universal and specific. Finally, the self-awareness training is to help participants identify attitudes, opinions, and biases that influence the way they communicate.

Among these training programs the affective training, cognitive training, self-awareness training, and cultural awareness training focus on the cognitive and affective understanding of one's own as well as the host culture. The area simulation training and the behavioral training focus on the teaching of "specific behaviors" that are used to better adjust to a new culture. Seidel's (1981) integrated the purposes of these training programs into sensitivity approach that clearly defines specific spheres of training in the three areas: appreciation and sensitivity (affective), understanding and awareness (cognitive), and skills (behavioral).

There is also a lack of any analysis (assessment) of students' intercultural competence at the self-report level, e.g. through pre-tests and post-tests, as suggested, for example, by Deardorff (2006). The author also suggests other possible means of gauging intercultural competence, both qualitative (interviews, observation, case studies, narrative) and quantitative. These are also accompanied by a number of recommendations.

We can present some questions and recommendations for further research surveys aimed at verifying whether the acquisition of a certain level of intercultural understanding is merely superficial, i.e. whether the students relate the knowledge they have gained concerning the cultural norms of a particular country to deeper values and cultural prerequisites, for example.

After determining how students described the skills they acquired during their experience of living abroad, the following question arises: How is it possible to develop cooperation between intercultural communication and intercultural education in order to enable us to help create an education system that assures more effective teaching and the development of intercultural competence?

\section{Conclusion}

This study was devoted to the topic of intercultural competence in students of tertiary education. The article presents the results of our research, which aimed to determine which components of intercultural competence students mastered during a study visit abroad. Data was acquired through phenomenological interviews, in which 
the participants were asked to reflect on their experience with mobility and describe the importance it had for them, particularly in relation to the development of the aforementioned competences.

Based on the results of our research we present recommendations for the development of these key competences through ideas such as "pre-departure intercultural training", which would help students to find their way around their new environment and gain a deeper understanding of the cultural context.

\section{References}

Bennett, J. M. (2009). Cultivating intercultural competence: A process perspective. In D. K. Deardorff (Ed.), The SAGE handbook of intercultural competence (pp. 121-140). Thousand Oaks, CA: Sage.

Brake, T. (1997). The global leader: Critical factors for creating the world class organization. Chicago: Irwin.

Bryman, A. (2012). Social research methods (4th ed.). New York: Oxford University Press, xli, 766 s.

Cargile, A. C., \& Giles, H. (1996). Intercultural communication training: Review, critique, and a new theoretical framework. Communication Yearbook, 19, 385-423.

Chen, G. M. (1990). Intercultural communication competence: Some perspectives of research. The Howard Journal of Communications, 2, 243-261. http://dx.doi.org/10.1080/10646179009359718

Creswell, J. W. (1998). Qualitative inquiry and research design: Choosing among five traditions. Thousand Oaks: Sage Publications.

Deardorff, D. K. (2004). Identification and Assessment of Intercultural Competence as a Student Outcome of Internationalization at Institutions of Higher Education in the United States (Dissertation). North Carolina, Raleigh: North Carolina State University.

Deardorff, D. K. (2006). Identification and assessment of intercultural competence as a student outcome of internationalization. Journal of Studies in Intercultural Education, 10, 241- 266. http://dx.doi.org/10.1177/ 1028315306287002

Fantini, A. E. (2000). A Central Concern: Developing Intercultural Competence. In SIT Occasional Papers.

Gudykunst, W. B., Hammer, M. R., \& Wiseman, R. L. (1977). An analysis of an integrated approach to cross-cultural training. International Journal of Intercultural Relations, 2, 99-110. http://dx.doi.org/10. 1016/0147-1767(77)90045-1

Gudykunst, W. B., Ting-Toomey, S., \& Wiseman, R. (1991). Taming the beast: Designing a course in intercultural communication. Communication Quarterly, 40, 272-286. http://dx.doi.org/10.1080/036345 29109378851

Hammer, M. R., Gudykunst, W. B., \& Wiseman, R. L. (1978). Dimensions of intercultural effectiveness: An exploratory study. International Journal of Intercultural Relations, 2, 382-393. http://dx.doi.org/10.1016/ 0147-1767(78)90036-6

Hendl, J. (2008). Kvalitativní výzkum: Základni teorie, metody a aplikace. Praha: Portál.

Hunter, B., White, G. P., \& Godbey, G. C. (2006). What does it mean to be globally competent? Journal of Studies in International Education, 10, 267-285. http://dx.doi.org/10.1177/1028315306286930

Janebová, E. (2009). Vedení internacionalizace vysokých škol. Studia paedagogica, 14(2).

Kim, Y. Y. (1991). Intercultural communication competence: A systems-theoretic view. In S. Ting-Toomey, \& F. Korzenny (Eds.), International and Intercultural communication annual 17: Cross cultural interpersonal communication (pp. 259-275). Newbury Park, CA: Sage.

Kim, Y. Y. (2009). The Identity Factor in Intercultural Competence. In D. K. Deardorff (Ed.), The Sage Handbook of Intercultural Competence. CA: SAGE.

Morgan, E., \& Weigel, V. (1988). Credits and credibility: Educating professionals for cultural sensitivity. Paper presented at the Conference on Science and Technology for International Development, Myrtle Beach, SC.

Morgensternová, M., \& Šulová, L. a kol. (2009). Interkulturní psychologie: Rozvoj interkulturní sensitivity. Praha: Karolinum.

Pusch, M. (1994). The Chameleon Capacity. In R. D. Lambert (Ed.), Educational exchange and global competence (pp. 205-210). New York: Council on International Educational Exchange.

Ruben, B. D. (1977). Guidelines for cross-cultural communication effectiveness. Group \& Organization Studies, 2, 470-479. http://dx.doi.org/10.1177/105960117700200408 
Ruben, B. D., \& Kealey, D. J. (1979). Behavioral assessment of communication competency and the prediction of cross-cultural adaptation. International Journal of Intercultural Relations, 3, 15-47. http://dx.doi.org/10.1016/0147-1767(79)90045-2

Seidel, G. (1981). Cross-cultural training procedures: Their theoretical framework and evaluation. In S. Bochner (Ed.), The mediating person: Bridge between cultures. Cambridge: Schenhman.

Series Addressing Intercultural Education, Training \& Service. [online]. [cit. 10-06-2015]. Retrieved from http://citeseerx.ist.psu.edu/viewdoc/download?doi=10.1.1.117.8512\&rep=rep1\&type=pdf\#page=33

Spitzberg, B. H. (1989). Issues in the development of a theory of interpersonal competence in the intercultural context. International Journal of Intercultural Relations, 13, 241-268. http://dx.doi.org/10.1177/105960 117700200408

Ting-Toomey, S. (2009). Intercultural Conflict Competence as a Facet of Intercultural Competence Development. In D. K. Deardorff (Ed.), The Sage Handbook of Intercultural Competence. CA: SAGE.

Van Maanen, J. (1988). Tales of the field: on writing ethnography. Chicago: University of Chicago Press.

\section{Copyrights}

Copyright for this article is retained by the author(s), with first publication rights granted to the journal.

This is an open-access article distributed under the terms and conditions of the Creative Commons Attribution license (http://creativecommons.org/licenses/by/3.0/). 